\title{
The effect of a short animated educational video on knowledge among glaucoma patients
}

This article was published in the following Dove Press journal:

Clinical Ophthalmology

\author{
Adi Mohammed Al \\ Owaifeer ${ }^{1,2}$ \\ Shaimaa Mohammed \\ Alrefaie ${ }^{3}$ \\ Zainah Mohameddia \\ Alsawah ${ }^{3}$ \\ Abdulaziz Ahmed Al Taisan' \\ Ahmed Mousa ${ }^{3}$ \\ Sameer I Ahmad 2,4,5 \\ 'Faculty of Ophthalmology, College \\ of Medicine, King Faisal University, \\ Al-Hasa, Saudi Arabia; ${ }^{2}$ King \\ Khaled Eye Specialist Hospital, \\ Riyadh, Saudi Arabia; ${ }^{3}$ Department \\ of Ophthalmology, College of \\ Medicine, King Saud University, \\ Riyadh, Saudi Arabia; ${ }^{4}$ Department \\ of Ophthalmology and Visual \\ Sciences, University of Maryland \\ School of Medicine, Baltimore, MD \\ USA; ${ }^{5}$ Glaucoma Consultants of \\ Washington, Herndon, VA, USA
}

Correspondence: Adi Mohammed Al Owaifeer

Faculty of Ophthalmology, College of Medicine, King Faisal University, PO

Box 400, Al-Hasa 31982, Saudi Arabia

Tel $+966 \quad 135808573$

Fax +966 135800820

Email dr.alowaifeer@hotmail.com
Purpose: To evaluate the effectiveness of an educational video in increasing knowledge among glaucoma patients and to determine the factors that may influence a patient's level of knowledge.

Patients and methods: This was a pre-post intervention study on adult glaucoma patients attending the outpatient service at King Khaled Eye Specialist Hospital. The intervention tested was a short educational video that was edited specifically for this study. All patients completed a pre-video and post-video knowledge questionnaire; moreover, sociodemographic and clinical characteristics were obtained.

Results: The total number of patients included was 196. The mean age of patients was $55.7 \pm 15.5$ years. Overall, $55.1 \%$ were males, $29.6 \%$ were illiterate, $85.2 \%$ resided in an urban area, $62.8 \%$ had a low income, and $41.8 \%$ were unemployed. The mean pre-intervention knowledge score was 6 out of 17, and the post-intervention score was $11.1(P \leq 0.001)$. Predictors of a poor knowledge score were old age ( $>60$ years), female sex, illiteracy, rural residence, low income, unemployment, and a negative family history of glaucoma.

Conclusion: The evaluated video intervention was effective in a short-term increase in knowledge among glaucoma patients. This tool may serve as an alternative to traditional educational methods.

Keywords: glaucoma, education, questionnaire, video, animation

\section{Introduction}

Glaucoma is a leading cause of irreversible blindness worldwide, with approximately 4.5 million people blind from the disease. ${ }^{1}$ The chronic nature of glaucoma necessitates lifelong adherence to treatment in order to minimize and avoid visual disability. ${ }^{2}$ Patients' level of education and knowledge about their condition is an important aspect of management in any chronic disease, including glaucoma. It has been shown that patients with a low level of formal education are at higher risk for a sustained decrease of visual acuity and visual field. ${ }^{3}$

Decreasing intraocular pressure (IOP) is the only method that has been proven effective in minimizing the progression of glaucoma. ${ }^{4}$ This is achieved mainly by the use of topical ocular hypotensive medications. ${ }^{5}$ Poor adherence to these topical medications is a challenging problem facing both ophthalmologists and glaucoma patients. The percentage of glaucoma patients not compliant to glaucoma medications can be as high as 59\%. ${ }^{6}$ This noncompliance may be mistaken for failure of therapy, which in turn may lead to unnecessary changes in the treatment plan (ie, prescribing additional medications or performing surgery). Poor knowledge about glaucoma is one of the barriers to topical medication adherence, which has been cited in the literature. ${ }^{7}$ Patients who do not understand the consequences of glaucoma and are unaware of the 
possible devastating visual disability that might occur if the disease is uncontrolled are less likely to comply with their prescribed treatment. ${ }^{7}$

Many educational interventions have been proposed to improve knowledge and adherence in patients with glaucoma such as nurse-led education, ${ }^{8}$ motivational interviewing, ${ }^{9}$ and group education. ${ }^{10}$ The use of videos as an educational intervention is an approach that has been proved to be effective in many areas of medicine. ${ }^{11}$ Video education has been shown to be superior to written information in terms of patient satisfaction and information gain. ${ }^{12}$

In this study, we aimed to test the effect of a short educational video on knowledge among glaucoma patients and to identify potential patient-related factors that may influence knowledge about glaucoma.

\section{Patients and methods}

The study protocol was approved by the Institutional Review Board at King Khalid Eye Specialist Hospital (KKESH). A pre-post intervention study design was used. Patients attending the glaucoma outpatient clinic at KKESH were approached to participate in this study. Patient enrollment took place from December 2016 through March 2017. Adults ( $\geq 18$ years) who had a confirmed diagnosis of glaucoma for 6 months or more were included in this study. Exclusion criteria were recent glaucoma diagnosis, a best-corrected visual acuity $\leq 20 / 200$ in the better seeing eye, and having any hearing disability or cognitive dysfunction.

\section{Study design}

Eligible patients were invited to join the study during a regular glaucoma visit, and those who agreed were given an information sheet containing all the details pertinent to their participation, and appropriate written informed consent was obtained. First, an interviewer (research assistant) administered the questionnaire (pre-test). Next, the participants watched the educational video on a laptop screen (at least 13 inches), once only. Upon completion of the video, the glaucoma knowledge section in the questionnaire (post-test) was filled out again.

\section{Questionnaire}

The questionnaire was divided into three sections: 1) sociodemographic information, 2) clinical indices, and 3) glaucoma knowledge assessment. The sociodemographic data included: age, sex, education, residence, region, monthly income, and occupational status. The clinical indices recorded were systemic diseases, ocular comorbidities, duration of glaucoma diagnosis, family history of glaucoma, glaucoma subtype, number of medications used, previous intervention (glaucoma surgery or laser, eg, trabeculoplasty), and glaucoma severity. Glaucoma severity was defined on the basis of mean deviation (MD) in the patient's most recent reliable visual field: mild $(\mathrm{MD}>-6 \mathrm{~dB})$, moderate $(\mathrm{MD} \leq-6 \mathrm{~dB}$ to $\geq-12 \mathrm{~dB}$ ), and severe $(\mathrm{MD}<-12 \mathrm{~dB})$. The patients were classified according to the worst eye visual field. ${ }^{13}$

Glaucoma knowledge was assessed by implementing an 11 -item questionnaire previously developed and validated. ${ }^{14}$ Each question was scored individually from 1 to 3 , with a maximum score of 17 . The questionnaire was translated into Arabic by utilizing the World Health Organization protocol for translation and adaptation. ${ }^{15}$ The process was started by a bilingual primary translator, speaking both English and Arabic, who is an ophthalmology resident familiar with common terminology used in glaucoma care in both languages. The questionnaire was translated into an Arabic version, with focus on cross-cultural, rather than linguistic, equivalence. Next, an expert panel, consisting of four local glaucoma specialists, reviewed the Arabic version of the questionnaire and modified the content to best suit the proposed study population. Discrepancies in two statements were identified and resolved. In the following step, the questionnaire was back-translated to English by an independent translator. Again, the back-translated version was reviewed for any discrepancy. Lastly, the final version was pre-tested on 10 respondents of different sociodemographic status that were representative of our study population. Words that were not completely understood by the respondents were replaced.

\section{Video}

A 3-min, animated, motion graphics, glaucoma educational video was written and directed by the project's primary investigator (AA). Simple Arabic words and phrases were used during writing the script, avoiding use of any sophisticated medical terminology to facilitate comprehension. The information conveyed can be divided into two main sections. The first section discusses general information about glaucoma, such as the chronic nature of the disease, its effect on the optic nerve, and resultant visual field loss. The second section focuses on important clinical details such as the necessity of ongoing follow-up visits, routine glaucoma testing (ie, IOP, visual field, optic nerve head examination), and glaucoma treatment. Certain analogies were used to explain and further clarify concepts discussed in the video. For example, the audience was told to think of glaucoma as 
a chronic problem "similar to diabetes and hypertension" that are lifelong. Upon completion, a panel of Arabic-speaking glaucoma specialists reviewed the video for validity and cultural appropriateness.

\section{Outcome measures}

The main outcome measure was change in knowledge score. The secondary outcome was the effect of certain sociodemographic factors and clinical indices on knowledge score.

\section{Statistical analyses}

Sociodemographic characteristics and clinical indices were summarized using descriptive statistics. The difference between pre- and post-intervention knowledge scores was calculated by using paired sample $t$-test. Analysis of variance (ANOVA) was used to examine the effect of certain sociodemographic and clinical variables (age, sex, education, residence, income, occupational status, duration of glaucoma diagnosis, family history of glaucoma, number of glaucoma medications used, history of a previous glaucoma intervention, and glaucoma severity) on knowledge score. Significance levels were determined at a $P$-value of $<0.05$. All data analyses were performed with the SPSS statistical software (version 19.0 for Windows, SPSS, Chicago, IL, USA).

\section{Results}

The total number of glaucoma patients included in this study was 196. Sociodemographic details of the participants are shown in Table 1. The mean age of the studied patients was $55.7 \pm 15.5$ years, with $52 \%$ of them being 60 years or younger, and $55.1 \%$ males. A total of $29.6 \%$ were illiterate, while the remainder had some form of education, ranging from primary school to higher degrees. The majority of patients (85.2\%) resided in an urban area, predominantly from the central region of Saudi Arabia. Most of the patients $(74.5 \%)$ were either retired or unemployed, with a monthly income of less than 10,000 SAR (2,666 USD) (62.8\%).

Glaucoma was discovered incidentally in 69 patients (35.2\%), as an ocular emergency with elevated IOP in 62 patients $(31.6 \%)$, following a complain of subjective visual loss in 43 patients (21.9\%), through a screening visit intended for glaucoma in 13 patients $(6.6 \%)$, and diagnosed at birth, "congenital glaucoma", in nine patients (4.6\%). The most common systemic disease was diabetes mellitus (49\%), and the most common ocular comorbidity was cataract $(42.9 \%)$. The majority had been diagnosed with glaucoma for more than 5 years $(63.3 \%)$ and did not have a positive
Table I Sociodemographic characteristics of the study population $(n=196)$

\begin{tabular}{|c|c|}
\hline Characteristics & n (\%) \\
\hline \multicolumn{2}{|l|}{ Age (years) } \\
\hline$\leq 60$ & $102(52.0)$ \\
\hline$>60$ & $94(48.0)$ \\
\hline \multicolumn{2}{|l|}{ Sex } \\
\hline Male & $108(55.1)$ \\
\hline Female & $88(44.9)$ \\
\hline \multicolumn{2}{|l|}{ Education } \\
\hline Illiterate & $58(29.6)$ \\
\hline Primary & $33(16.8)$ \\
\hline Intermediate & $25(12.8)$ \\
\hline Secondary & $35(17.9)$ \\
\hline Higher & $45(23.0)$ \\
\hline \multicolumn{2}{|l|}{ Residence } \\
\hline Urban & $167(85.2)$ \\
\hline Rural & $29(14.8)$ \\
\hline \multicolumn{2}{|l|}{ Region } \\
\hline Central & II 17 (59.7) \\
\hline Eastern & $15(7.7)$ \\
\hline Western & $19(9.7)$ \\
\hline Northern & II (5.6) \\
\hline Southern & $34(17.3)$ \\
\hline \multicolumn{2}{|l|}{ Income (monthly) } \\
\hline$<10,000$ SAR $(2,666$ USD $)$ & $123(62.8)$ \\
\hline $10,000-20,000$ SAR $(2,666-5,332$ USD) & $73(37.2)$ \\
\hline \multicolumn{2}{|l|}{ Occupational status } \\
\hline Governmental & $31(15.8)$ \\
\hline Private sector & $7(3.6)$ \\
\hline Retired & $64(32.7)$ \\
\hline Student & $12(6.1)$ \\
\hline Unemployed & $82(4 \mid .8)$ \\
\hline
\end{tabular}

Abbreviations: SAR, Saudi Arabian Riyal; USD, United States dollars.

family history (64.3\%). Detailed clinical indices of the study population are shown in Table 2.

The mean pre-intervention knowledge score was $6(\mathrm{SD}=3.9)$ out of 17 (range=0-16). Approximately onethird of the study population (34.7\%) had a pre-intervention knowledge score of $\leq 3$. A correct definition of glaucoma was reached in only $37.8 \%$ of patients. One hundred and twenty-three patients (62.7\%) did not know which part of the eye was affected by glaucoma, and only 52 patients (26.5\%) could name their drops. Post-intervention knowledge score increased up to 11.1 ( $\mathrm{SD}=3.2$; range=3-17). Nearly twothirds of patients (63.8\%) had a post-intervention knowledge score of $\geq 11$. Upon comparing pre- and post-intervention knowledge scores, there was a statistically significant difference $(P \leq 0.001)$.

Factors influencing the patients' knowledge score (postintervention) are shown in Table 3. Better knowledge scores were observed in patients who were younger than 60 years, were males, had a higher degree of education, resided in an 
Table 2 Clinical indices of the study population $(n=196)$

\begin{tabular}{ll}
\hline Indices & $\mathbf{n}(\%)$ \\
\hline Systemic diseases & \\
Diabetes mellitus & $96(49.0)$ \\
Hypertension & $73(37.2)$ \\
Coronary heart disease & $16(8.2)$ \\
Dyslipidemia & $57(29.1)$ \\
Bronchial asthma & $17(8.7)$ \\
Ocular comorbidities & \\
Cataract & $84(42.9)$ \\
Diabetic retinopathy & $31(15.8)$ \\
Corneal disease & $23(11.7)$ \\
Ocular trauma & $8(4.1)$ \\
Duration of glaucoma diagnosis & \\
$\quad \leq 5$ years & $72(36.7)$ \\
>5 years & $124(63.3)$ \\
Family history of glaucoma & \\
Yes & $70(35.7)$ \\
No & $126(64.3)$ \\
Glaucoma diagnosis & \\
Primary angle closure & $71(36.2)$ \\
Primary open angle & $54(27.6)$ \\
Pseudoexfoliation & $21(10.7)$ \\
Congenital & $9(4.6)$ \\
Uveitic & $9(4.6)$ \\
Other & $32(16.3)$ \\
Number of glaucoma medications & \\
S2 & $98(50.0)$ \\
Previous glaucoma intervention (ie, surgery, laser) & $98(50.0)$ \\
Yes & \\
No & $117(59.7)$ \\
Glaucoma severity & $79(40.3)$ \\
Mild & \\
Moderate & $31(15.8)$ \\
Severe & $25(12.8)$ \\
\hline
\end{tabular}

urban area, had a higher income, and had a positive family history of glaucoma. Being unemployed was associated with a low knowledge score. Factors such as duration of glaucoma, number of medications, history of a previous glaucoma intervention, and glaucoma severity did not show a statistically significant influence.

\section{Discussion}

To the best of our knowledge, this is the first study in the literature that tests a scientifically validated and culturally appropriate video intervention to improve knowledge among Saudi glaucoma patients. The educational intervention tested in our study was a motion graphics video. Multimedia materials have been used widely to communicate health-related messages to the general population, improve patients' knowledge about specific diseases, and aid in management of certain illnesses. Videos have been applied previously in many
Table 3 Factors influencing knowledge score (post-intervention)

\begin{tabular}{|c|c|c|c|}
\hline Indices & Mean & $\mathbf{F}$ & $P$-value \\
\hline \multicolumn{4}{|l|}{ Age (years) } \\
\hline$\leq 60$ & 12.24 & 32.912 & $<0.001$ \\
\hline$>60$ & 9.79 & & \\
\hline \multicolumn{4}{|l|}{ Sex } \\
\hline Male & 11.67 & 8.849 & 0.003 \\
\hline Female & 10.32 & & \\
\hline \multicolumn{4}{|l|}{ Education } \\
\hline Illiterate & 8.76 & 28.496 & $<0.001$ \\
\hline Primary & 9.79 & & \\
\hline Intermediate & 11.36 & & \\
\hline Secondary & 12.37 & & \\
\hline Higher & 13.78 & & \\
\hline \multicolumn{4}{|l|}{ Residence } \\
\hline Urban & 11.37 & 11.003 & $<0.001$ \\
\hline Rural & 9.28 & & \\
\hline \multicolumn{4}{|l|}{ Income (monthly) } \\
\hline$<10,000$ SAR $(2,666$ USD $)$ & 10.38 & 16.906 & $<0.001$ \\
\hline $10,000-20,000$ SAR $(2,666-5,332$ USD) & 12.27 & & \\
\hline \multicolumn{4}{|l|}{ Occupational status } \\
\hline Governmental & 12.90 & 11.229 & $<0.001$ \\
\hline Private sector & 13.29 & & \\
\hline Retired & 11.58 & & \\
\hline Student & 12.75 & & \\
\hline Unemployed & 9.52 & & \\
\hline \multicolumn{4}{|l|}{ Duration of glaucoma diagnosis } \\
\hline$\leq 5$ years & 10.61 & 2.371 & 0.125 \\
\hline$>5$ years & 11.34 & & \\
\hline \multicolumn{4}{|l|}{ Family history of glaucoma } \\
\hline Yes & 12.17 & 13.798 & $<0.001$ \\
\hline No & 10.44 & & \\
\hline \multicolumn{4}{|l|}{ Number of glaucoma medications } \\
\hline$\leq 2$ & 11.35 & 1.548 & 0.214 \\
\hline$>2$ & 10.78 & & \\
\hline \multicolumn{4}{|l|}{$\begin{array}{l}\text { Previous glaucoma intervention } \\
\text { (ie, surgery, laser) }\end{array}$} \\
\hline Yes & 10.85 & 1.196 & 0.275 \\
\hline No & 11.37 & & \\
\hline \multicolumn{4}{|l|}{ Glaucoma severity } \\
\hline Mild & 11.73 & 1.902 & 0.152 \\
\hline Moderate & 11.74 & & \\
\hline Severe & 10.76 & & \\
\hline
\end{tabular}

Abbreviations: F, degree of freedom; SAR, Saudi Arabian Riyal; USD, United States dollars.

aspects of glaucoma management, such as doctor-patient communication, ${ }^{16}$ proper eye drop instillation, ${ }^{17}$ and ocular massage following trabeculectomy surgery. ${ }^{18}$ Our results have shown that nearly $30 \%$ of the tested patients are illiterate. Given these low literacy levels of Saudi adult glaucoma patients, we believe that using multimedia in educating these patients is more appropriate compared to other traditional methods, eg, brochures, booklets, and pamphlets, as these interventions require a certain degree of literacy. 
A low baseline (pre-intervention) knowledge about glaucoma was noted in the tested population, the mean score was 6 out of 17 , and only $37.8 \%$ of patients could define glaucoma appropriately. Mansouri et a $\mathrm{l}^{19}$ conducted a cross-sectional survey on 200 glaucoma patients from two Swiss tertiary glaucoma clinics, and they found that only $28 \%$ of their sample could define glaucoma correctly. Comparing their results to ours, we note that our patient population scored slightly higher than the studied group in their cohort in terms of the ability to correctly define glaucoma.

The findings at baseline emphasize the educational needs from a glaucoma patient's standpoint. Saudi glaucoma patients require information on a range of domains such as definition of glaucoma, possible risk factors, pathophysiology, effect on vision, and treatment. According to a report published by AlHilali et al, ${ }^{20}$ obtaining information from an eye care provider is the preferred method listed by the majority of patients attending ophthalmic care in Saudi Arabia. This places an additional burden on treating ophthalmologists to bridge this gap in knowledge, a task that could be difficult to fulfill given a busy clinical practice and the overall shortage of local ophthalmologists with subspecialty training in glaucoma.

Our results showed that the tested educational video was effective in increasing mean knowledge scores from 6 up to 11.1 , a statistically significant difference. Rosenthal et $\mathrm{al}^{21}$ also tested an educational video to improve knowledge in both British and American individuals. Their results showed that the intervention applied was successful in improving knowledge, from $48 \%-64 \%$ up to $78 \%-88 \%$ of the questions answered correctly. Another study, performed by Kim et al, compared an educational session (consisting of a video and a brochure) to standard care in two groups of patients. They found that the group exposed to the educational intervention had a mean knowledge score of 18.9, compared to 15.5 in the unexposed group, a difference that was statistically significant. It is difficult to compare the results of our study against those tested by the other two reports, owing to the difference in methodologies, educational interventions, and means of knowledge assessment. However, it is possible to state that, from our study, the evidence supports the notion that patient education by videos may be an effective method in increasing knowledge among glaucoma patients.

Our secondary objective was to assess the influence of sociodemographic and clinical indices on knowledge. Younger age, male sex, a higher degree of education, urban residence, higher income, and a positive family history of glaucoma were predictors of good knowledge among our cohort.
This correlation is similar to one that has been reported by Hoevenaars et al, ${ }^{23}$ as they found better knowledge scores in younger patients and those from a higher socioeconomic group. On the contrary, other studies in the literature failed to show such an association. Blondeau et $\mathrm{al}^{24}$ studied the effect of a 2-h information session in improving understanding in glaucoma patients, and the only factor associated with a good knowledge score was younger age, below 60 years. Another study, by Costa et al, ${ }^{25}$ evaluated the knowledge in glaucoma patients from two centers, one in the United States and the other in Brazil, and in their group of patients, the only factor that was positively correlated with knowledge was the level of education.

The fact that certain clinical indices (ie, duration of diagnosis, number of medications, previous intervention, and glaucoma severity) did not have a positive influence on knowledge is potentially concerning. This signifies that, despite the patients' long-term follow-up with an ophthalmologist, little glaucoma knowledge has been built up over time. Furthermore, it reflects the inattentive attitude of our patients toward a chronic illness that they suffer from. Such elements can be targeted in planning additional educational interventions to help our glaucoma patients, in the future.

Our study has certain limitations. First, the comparison between pre- and post-intervention was carried out without the introduction of a control group. Second, given its noncomparative nature, we were unable to contrast video education with traditional methods in our population. However, as mentioned earlier, considering the low literacy level in our patients, it would be difficult to compare video versus other methods (that require a minimum level of literacy) without introducing bias while grouping patients. Another limitation is the fact that the post-test was carried out immediately after the video. Although this methodology tests the amount of knowledge acquired after the session, it fails to evaluate the long-term retention of such knowledge. These limitations can be addressed in future studies.

\section{Conclusion}

Our current study has shown that using a video as an educational tool is effective in increasing short-term knowledge among glaucoma patients. This may serve as an alternative method to traditional educational materials. Moreover, our study has identified patient-related factors that are associated with low knowledge scores, eg, old age, female sex, illiteracy, rural residence, low income, and unemployment. This subset of patients should receive more attention when planning future educational interventions. 


\section{Disclosure}

The authors report no conflicts of interest in this work.

\section{References}

1. Resnikoff S, Pascolini D, Etya'ale D, et al. Global data on visual impairment in the year 2002. Bull World Health Organ. 2004;82:844-851.

2. Forsman E, Kivelä T, Vesti E. Lifetime visual disability in openangle glaucoma and ocular hypertension. J Glaucoma. 2007;16(3): 313-392.

3. AGIS Investigators. The Advanced Glaucoma Intervention Study (AGIS): 12. Baseline risk factors for sustained loss of visual field and visual acuity in patients with advanced glaucoma. Am J Ophthalmol. 2002;134(4):499-512.

4. Leske MC, Heijl A, Hussein M, et al. Factors for glaucoma progression and the effect of treatment: the early manifest glaucoma trial. Arch Ophthalmol. 2003;121:48-56.

5. Kass MA, Heuer DK, Higginbotham EJ, et al. The Ocular Hypertension Treatment Study: a randomized trial determines that topical ocular hypotensive medication delays or prevents the onset of primary openangle glaucoma. Arch Ophthalmol. 2002;120:701-713.

6. Schwartz GF. Compliance and persistency in glaucoma follow-up treatment. Curr Opin Ophthalmol. 2005;16:114-121.

7. Lacey J, Cate H, Broadway DC. Barriers to adherence with glaucoma medications: a qualitative research study. Eye (Lond). 2009;23: 924-932.

8. Sheppard J, Warner J, Kelley K. An evaluation of the effectiveness of a nurse-led glaucoma monitoring clinic. Ophthalmic Nurs Int $J$ Ophthalmic Nurs. 2003;7:15-21.

9. Cook PF, Bremer RW, Ayala AJ, Kahook MY. Feasibility of motivational interviewing delivered by a glaucoma educator to improve medication adherence. Clin Ophthalmol. 2010;4:1091-1101.

10. Chen X, Chen Y, Sun X. Notable role of glaucoma club on patients' knowledge of glaucoma. Clin Exp Ophthalmol. 2009;37:590-594.

11. Calderón JL, Shaheen M, Hays RD, Fleming ES, Norris KC, Baker RS. Improving diabetes health literacy by animation. Diabetes Educ. 2014; 40(3):361-372.

12. Snyder-Ramos SA, Seintsch H, Böttiger BW, Motsch J, Martin E, Bauer M. Patient satisfaction and information gain after the preanesthetic visit: a comparison of face-to-face interview, brochure, and video. Anesth Analg. 2005;100(6):1753-1758.
13. Mills RP, Budenz DL, Lee PP, et al. Categorizing the stage of glaucoma from pre-diagnosis to end-stage disease. Am J Ophthalmol. 2006; 141(1):24-30.

14. Gray TA, Fenerty C, Harper R, et al. Preliminary survey of educational support for patients prescribed ocular hypotensive therapy. Eye (Lond). 2010;24(12):1777-1786.

15. WHO [webpage on the Internet]. Process of Translation and Adaptation of Instruments. Geneva: WHO; 2013. Available from: http://www.who. int/substance_abuse/research_tools/translation/en. Accessed June 21, 2017.

16. Friedman DS, Hahn SR, Quigley HA, et al. Doctor-patient communication in glaucoma care: analysis of videotaped encounters in community-based office practice. Ophthalmology. 2009;116(12): 2277-2285.e1-e3.

17. Lazcano-Gomez G, Castillejos A, Kahook M, Jimenez-Roman J, Gonzalez-Salinas R. Videographic assessment of glaucoma drop instillation. J Curr Glaucoma Pract. 2015;9(2):47-50.

18. Hua L, Yingjuan L, Jingshu Z, Wei C. The effect of health education video on ocular massage after trabeculectomy. Comput Inform Nurs. 2014;32(6):294-298.

19. Mansouri K, Iliev ME, Rohrer K, Shaarawy T. Compliance and knowledge about glaucoma in patients at tertiary glaucoma units. Int Ophthalmol. 2011;31(5):369-376.

20. AlHilali SM, AlMuammar AM, AlKahtani E, Khandekar R, AlJasser AA. Preferred method of education among patients in ophthalmic care in Saudi Arabia. Middle East Afr J Ophthalmol. 2016; 23(2):168-171

21. Rosenthal AR, Zimmerman JF, Tanner J. Educating the glaucoma patient. Br J Ophthalmol. 1983;67(12):814-817.

22. Kim S, Stewart JF, Emond MJ, Reynolds AC, Leen MM, Mills RP. The effect of a brief education program on glaucoma patients. J Glaucoma. 1997;6(3):146-151.

23. Hoevenaars JG, Schouten JS, Van den Borne B, Beckers HJ, Webers CA. Socioeconomic differences in glaucoma patients' knowledge, need for information and expectations of treatments. Acta Ophthalmol Scand. 2006;84(1):84-91.

24. Blondeau P, Esper P, Mazerolle E. An information session for glaucoma patients. Can J Ophthalmol. 2007;42(6):816-820.

25. Costa VP, Spaeth GL, Smith M, Uddoh C, Vasconcellos JP, Kara-José N. Patient education in glaucoma: what do patients know about glaucoma? Arq Bras Oftalmol. 2006;69(6):923-927.
Clinical Ophthalmology

\section{Publish your work in this journal}

Clinical Ophthalmology is an international, peer-reviewed journal covering all subspecialties within ophthalmology. Key topics include: Optometry; Visual science; Pharmacology and drug therapy in eye diseases; Basic Sciences; Primary and Secondary eye care; Patient Safety and Quality of Care Improvements. This journal is indexed on

\section{Dovepress}

PubMed Central and CAS, and is the official journal of The Society of Clinical Ophthalmology (SCO). The manuscript management system is completely online and includes a very quick and fair peer-review system, which is all easy to use. Visit http://www.dovepress.com/ testimonials.php to read real quotes from published authors. 